\title{
BLEEDING DURING TRANSURETHRAL PROSTATIC SURGERY
}

\author{
JohN W. Desmond, M.B., B.S., F.R.C.P.(C), AND \\ R. A. GoRDon, M.D., F.R.C.P.(C), F.F.A.R.C.S.
}

ONE OF THE MORE SERIOUS COMPLICATIONS of transurethral prostatic surgery is haemorrhage. The patients subjected to this procedure are usually old, with myocardial disease and poor myocardial reserve, and they are occasionally hypovolaemic and dehydrated prior to surgery.

A review of the records of 60 patients who had recently had prostatic surgery disclosed that 70 per cent were between the ages of 70 and 90 years, while 67 per cent had documented and electrocardiographic evidence of myocardial disease (Table I). Exposing such a patient to the hazards of under-transfusion or over-transfusion, because of the inability to determine the amount of blood lost, increases the rnorbidity and mortality of this operation.

TABLE 1

Documented Cardiovascular Disease in 60 Consecutive Patients Reviewed during 1966

\begin{tabular}{lr}
\hline Previous history and electrocardiographic \\
$\quad$ evidence of myocardial infarction
\end{tabular}

Visual estimations of blood loss during the procedure are grossly inaccurate. We have demonstrated this in the following manner. Two identical bottles of 2 $\mathrm{L}$ capacity were flled with the irrigant solution used in our hospital during transurethral resections of the prostate (glycine $1.2 \%$ solution). Known quantities of blood were then added to the bottles. Experienced members of the urological, anaesthetic and nursing staffs were asked to estimate how much blood was in each bottle. The answers ranged from 300 to $1500 \mathrm{ml}$, the most frequent range being 600 to $700 \mathrm{ml}$. Actually there was only $40 \mathrm{ml}$ in one bottle and $100 \mathrm{ml}$ in the other. It became obvious that such a method of estimating blood loss in this type of surgery was grossly inaccurate and could lead to serious errors in blood replacement. These patients are already exposed to the dangers of fluid absorption through the venous sinuses during the resection, and over-transfusion may precipitate both left heart failure and excessive bleeding.

Blood loss during transurethral resection of the prostate may be measured with reasonable accuracy by collecting the irrigating fluid and determining the quantity of haemoglobin contained in it. This measurement may then be converted

"Department of Anaesthesia, University of Toronto and Toronto General Hospital. 
to a volume of whole blood by relating it to the haemoglobin content of the patient's blood. We have adopted this method as a routine. The irrigating fluid is collected in a $10 \mathrm{~L}$ pail. After thorough mixing with a paddle which also serves as a measuring device (Fig. 1) the haemoglobin content of this fluid is measured by a Fisher haemophotometer calibrated to measure dilute solutions of haemoglobin. From this measurement the volume of blood loss is readily calculated.

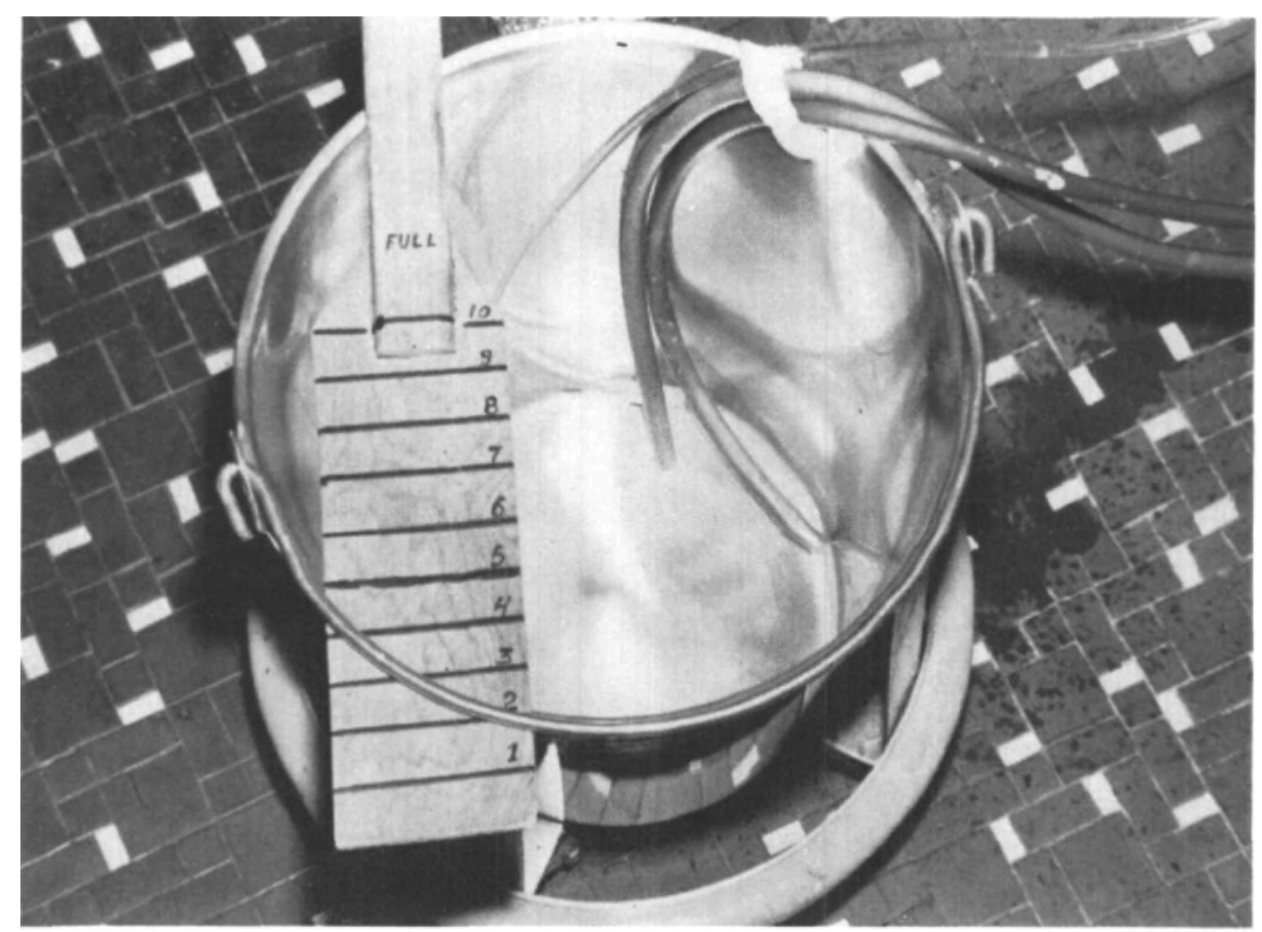

FIGURE 1. Pail and volume-measuring paddle used to collect irrigating fluid efluent.

The true measurement of blood loss has led to rational blood replacement, and has in particular reduced the amount of blood transfused to the patients. During the eight-month period preceding the institution of routine measurement of blood loss, 107 patients received 171 units of blood. In a similar period, during which blood replacement was controlled by actual measurement of loss, 119 patients required only 66 units. We interpret this as indicating that many patients were over-transfused when loss was estimated rather than measured.

A variety of factors influence bleeding during and after transurethral resection of the prostate (Table II). We believe that the increase in venous pressure resulting from overloading of the circulation by excessive transfusion is an important factor. This would appear to be borne out by the fact that of the 107 patients resected during the eight-month period in our study when a large quantity of blood was used, it was necessary to return three to the operating room for control of haemorrhage, while this necessity has not arisen in any of 350 subsequent patients in whom volume replacement was controlled by actual measurement of blood loss. 
TABLE II

Factors Influencing Haimorrhage

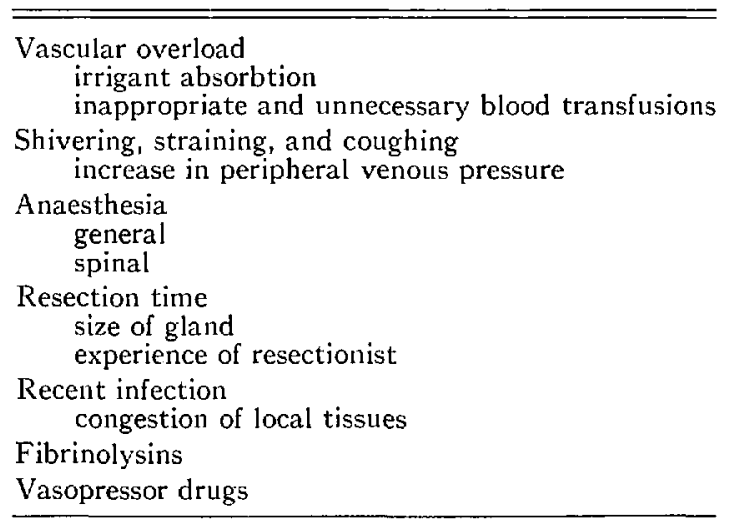

It has been our purpose to investigate factors causing haemorrhage during transurethral prostatic resection, and to determine how these may be regulated.

\section{Increase venous pressure}

Any factor which increases the peripheral venous pressure will increase bleeding during transurethral resection of the prostate. When the central venous pressure reaches the value of the extravascular tissue pressure the intraluminal pressure will prevent collapse of the veins, and the peripheral venous pressure will from that point increase in parallel with the central venous pressure. ${ }^{1}$

The central venous pressure was measured in 30 patients in this study. It was evident that when central venous pressure was increased from any cause, bleeding became profused and occasionally uncontrollable.

\section{Effect of general anaesthesia}

General anaesthesia in these patients was induced with a "sleep dose" of thiopentone and maintained with nitrous oxide, halothane, and oxygen, using a semiopen or semi-closed circuit.

General anaesthesia must be relatively deep for this procedure; analgesia must be profound. Halothane and nitrous oxide provided inadequate analgesia in light planes of anaesthesia. Under light anaesthesia the abdominal muscles immediately became tense when the resection commenced; at the same time the central venous pressure rose dramatically, and bleeding was severe. Figure 2 demonstrates such a case, in which central venous pressure rose to $31 \mathrm{~cm}$ of water. Deep surgical anaesthesia is required to prevent this reaction.

\section{Effect of spinal anaesthesia}

Spinal anaesthesia in this series was produced by the use of hyperbaric tetracaine (Pontocaine (1)). The patients were kept in the head-up position by bolstering the head and back with pillows, to keep the level of the spinal block low.

The central venous pressure under spinal anaesthesia usually fell from a "normal" of $6 \mathrm{~cm}$ of water to 2 to $4 \mathrm{~cm}$ of water. There was no straining under spinal 


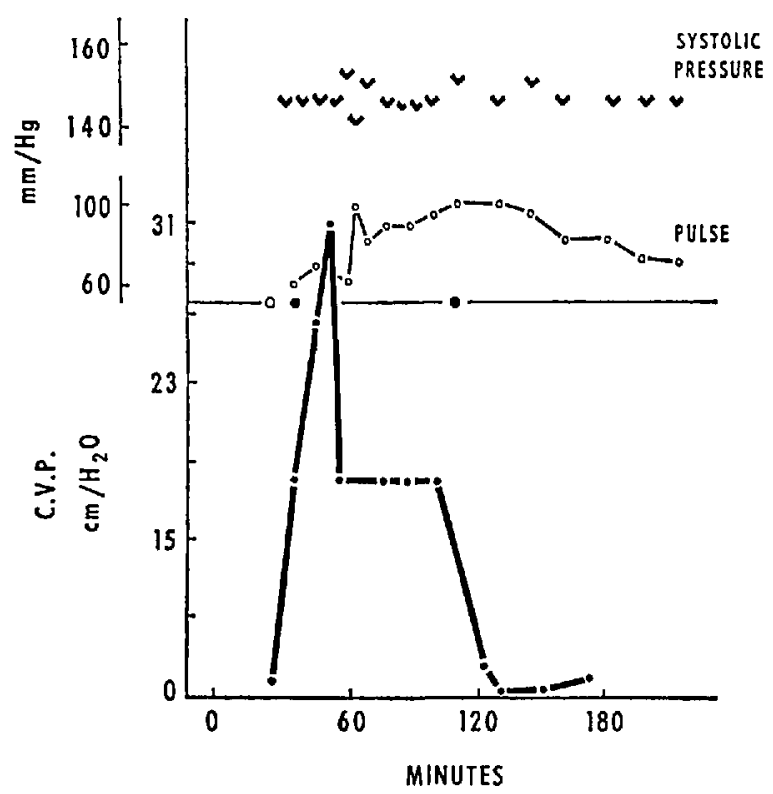

FIGURe 2, Rise in central venous pressure at beginning of resection under light general anaesthesia.
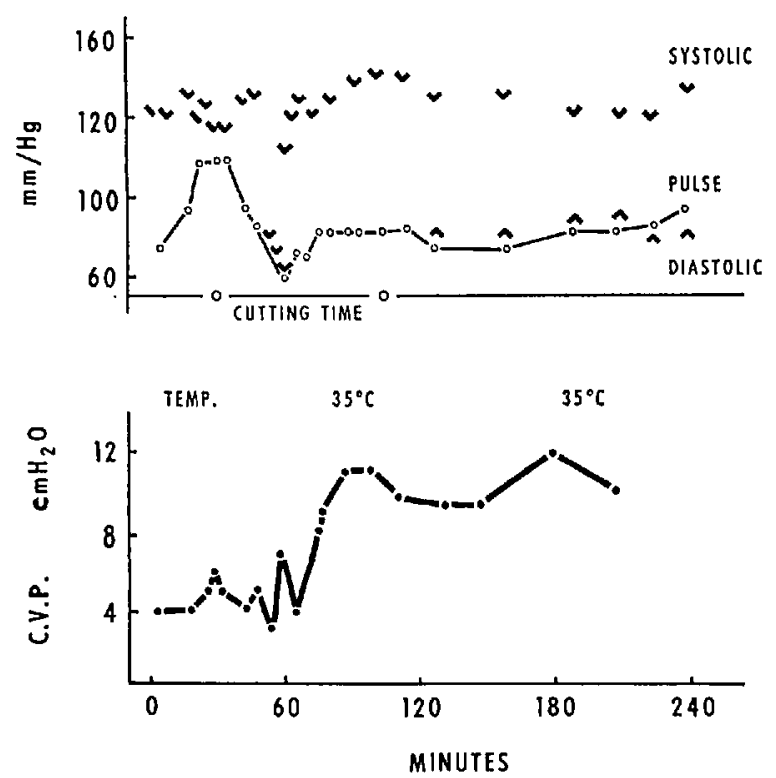

Figure 3. The initial fall in central venous pressure on induction of spinal anaesthesia. It was followed by a marked rise when shivering occurred.

anaesthesia. The vasodilatation which occurs with spinal anaesthesia combined venous pressure increased and bleeding ensued (Fig. 3).

Bleeding under spinal anaesthesia is no less than that during adequate general anaesthesia. The vasodilatation which occurs with spinal anaesthesia combined 
DESMOND \& GORDON: BLEEDING DURING PROSTATIC SURGERY

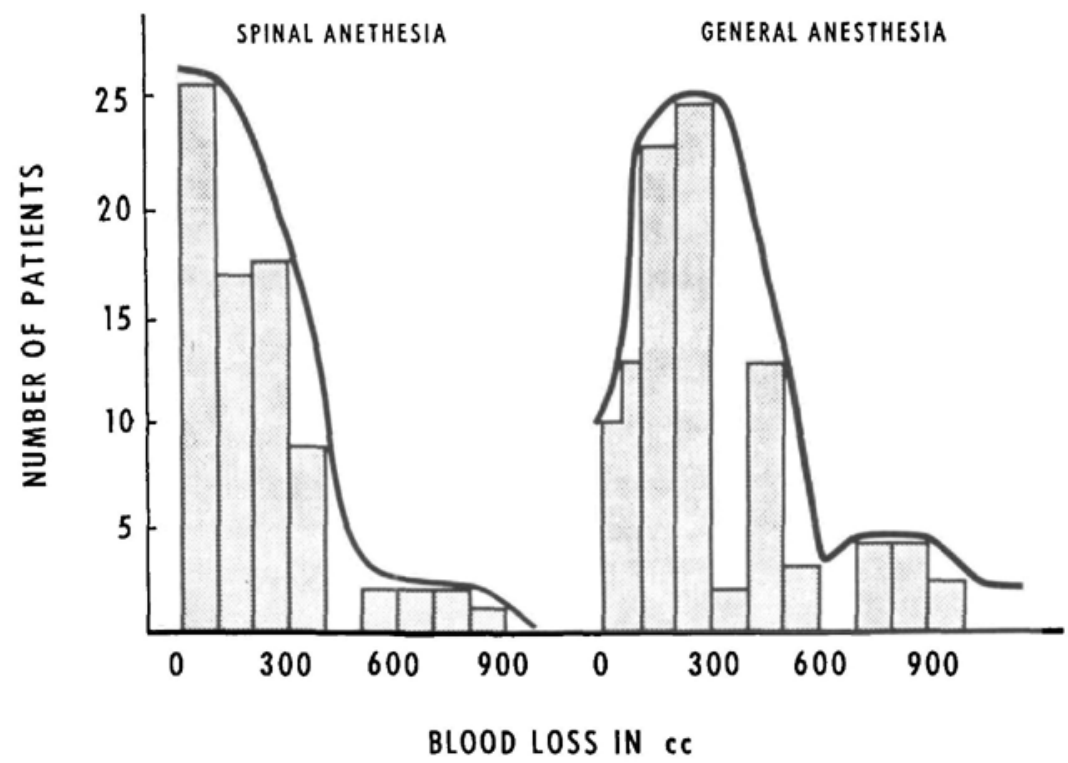

Figure 4. Comparison of blood loss under spinal anaesthesia and general anaesthesia. There is no significant difference.

with the head-up lithotomy position will increase the pooling of blood and the venous pressure in the pelvis and in the prostatic venous sinuses (Fig. 4).

\section{Effect of length of operation}

Measured blood loss was plotted against length of operation in minutes in 170 patients during the study. The results are shown in Figure 5. Blood loss was usually between 200 and $300 \mathrm{ml}$ when the resection time was one hour or less. When the operating time exceeded one hour, blood loss was disproportionately increased. The relationship of this increase to absorption of irrigating fluid is suspected but has not been demonstrated in this study.

\section{Effect of vascular overload with irrigating fluid}

Absorption of irrigating fluid through the venous sinuses must be recognized early. Close monitoring of central venous pressure, systolic and diastolic pressure, and pulse will usually indicate to the anaesthetist that fluid absorption is occurring. Haemorrhage is always greater in these cases.

Taylor et $a l_{.}{ }^{2}$ in 1958 showed that 68 per cent of patients had weight gains during prostatectomy averaging $1225 \mathrm{gm}$. In our own study some patients showed weight gains of $2.2 \mathrm{~kg}$ and blood volume increases up to $500 \mathrm{cc}$. A typical case of irrigant absorption is shown in Figure 6, in which the rapid increase in central venous pressure is seen, associated with a rise in systolic pressure in response to the vascular overload.

\section{Use of vasopressors}

The use of vasopressors in these patients is to be condemned. If a vasopressor is used in a patient with vascular overload, movement of excess fluid into the 


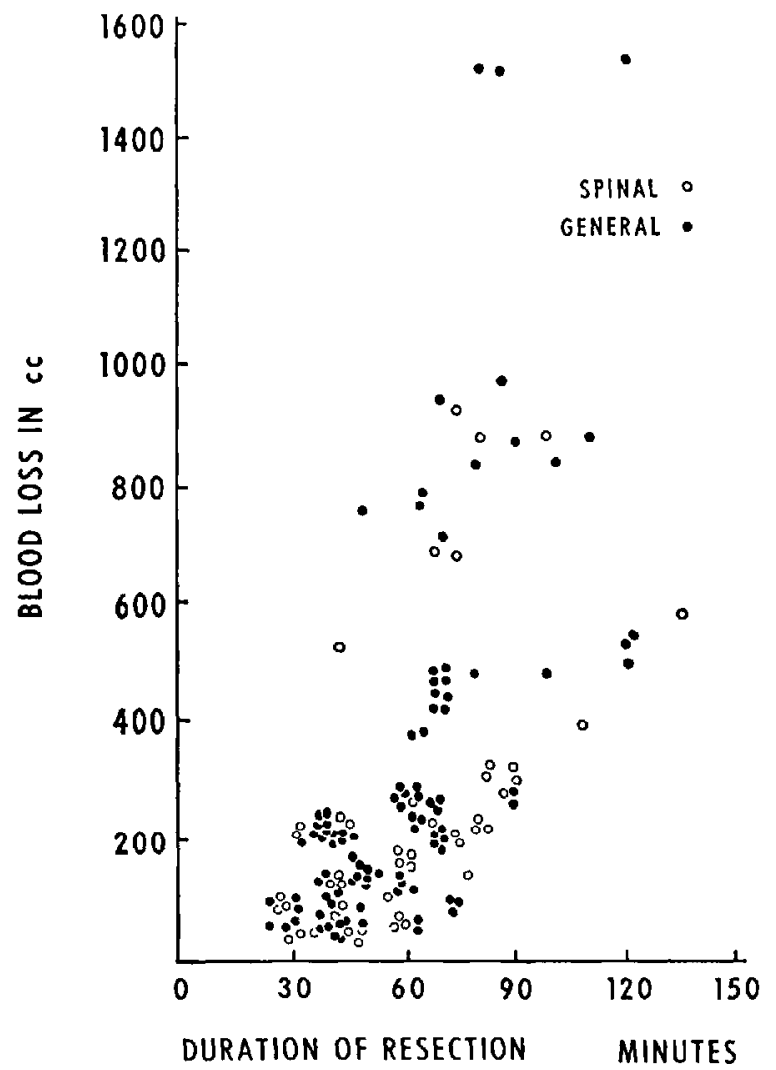

Figune 5. Blood loss is plotted against duration of the transurethral resection under both general and spinal anaesthesia. Blood loss is disproportionately increased in longer operations.

interstitial compartment is reduced, and the increase in intravascular pressure results in increased haemorrhage. Increased peripheral resistance added to vascular overload in these patients may lead in a significant proportion of cases to acute heart failure and to pulmonary oedema. Figure 7 illustrates this effect in one such patient. This patient developed pulmonary oedema, cerebral oedema, and severe dilutional hyponatraemic. Haemorrhage was also excessive in this case. Our preference, therefore, has been to bring the patient back another day rather than to utilize a vasopressor to restore blood pressure during resection. This particularly applies if hypotension occurs due to an inadvertantly high block with spinal anaesthesia.

\section{SUMmary}

Many factors influence bleeding during transurethral prostatic surgery. Some of these are unavoidable, while others can be avoided or corrected if the patient is carefully monitored by the anaesthetist. In many instances the resectionist can be given early warning of changes which are occurring so that he may bring the operation to an end. 
DESMOND \& GORDON: BLEEDING DURING PROSTATIC SURGERY

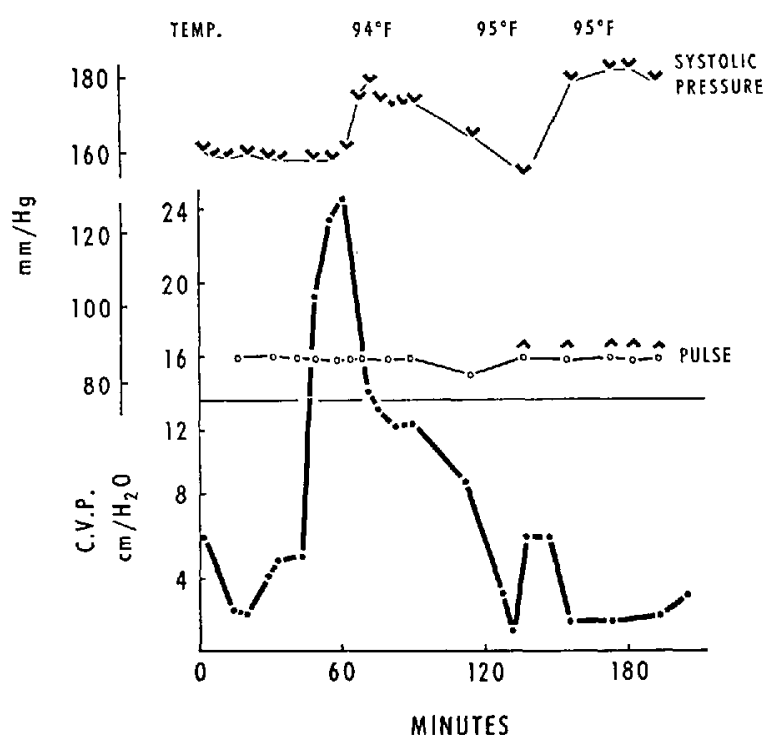

Figure 6. Rapid rise in central venous pressure and increase in systolic pressure due to absorption of irrigating fluid through the prostatic venous sinuses.

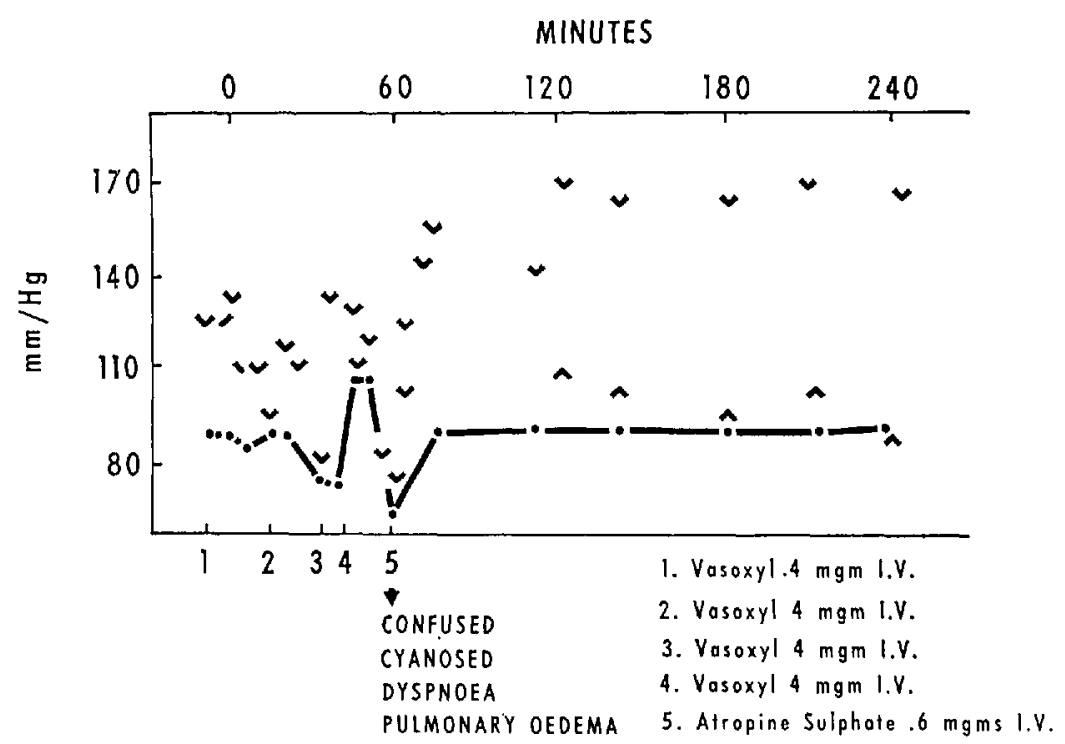

Figure 7. An example of the effect of administering a vasopressor to restore blood pressure during transurethral resection of the prostate.

Direct measurements of blood loss during transurethral prostatic surgery has proved invaluable, particularly in avoiding circulatory overload due to excessive blood transfusion. We have described a method of measuring blood loss which has proved practical as a routine operating room procedure. 
Any factor which raises venous pressure will lead to haemorrhage during transurethral prostatic surgery. These include straining during general anaesthesia, shivering during spinal anaesthesia, and circulatory overload by absorption of irrigating fluid or excessive transfusion. The usefulness of careful monitoring of the central venous pressure has been clearly shown.

General anaesthesia for transurethral prostatic resection must be deep enough to produce absolute analgesia and to prevent contraction of the abdominal muscles during the resection. Shivering must be avoided under spinal anaesthesia, since this raises the venous pressure and increases haemorrhage. The use of vasopressors must also be avoided.

Resection time should be limited to one hour, since there is a disproportionate increase in blood loss after that time.

\section{RÉSUMÉ}

$\mathrm{Au}$ cours de la résection transurétrale de la prostate, l'importance des pertes sanguines est influencée par plusieurs facteurs. Parmi ceux-ci, certains sont inévitables, d'autres sont évitables et peuvent être corrigés si l'anesthésiste fait un enregistrement soigneux des signes vitaux de son malade. Dans bien des cas, en renseignant précocement l'opérateur de changements qui apparaissent, il pourra abréger l'opération.

En mesurant directement les pertes sanguines au cours de la chirurgie prostatique transurétrale, on a receuilli des renseignements très précieux pour ces malades et plus particulièrement en prévenant la surcharge de la circulation en donnant des quantités excessive de sang. Nous avons décrit une façon de mesurer les pertes sanguines qui s'est avérée une routine pratique de la salle d'opération.

Tout facteur susceptible d'augmenter la tension veineuse va favoriser l'hémorragie au cours de la chirurgie de la prostate. Parmi ces facteurs, citons : des efforts au cours de l'anesthésie générale, des frissons au cours de l'anesthésie rachidienne, une surcharge de la circulation soit par absorption de l'eau d'irrigation soit par transfusions excessives. Nous avons clairement démontré l'utilité d'enregistrer minutieusement la tension veineuse centrale.

Pour la résection transurétrale de la prostate, l'anesthésie générale doit être assez profonde pour procurer une analgésie absolue et pour prévenir la contraction des muscles de l'abdomen durant la résection. Sous anesthésie rachidienne, il faut éviter les frissons car cela augmente la tension veineuse et favorise l'hémorragie. Chez ces malades, il ne faut pas employer de vasoconstricteurs.

La durée de la résection doit se limiter à une heure car, après une heure, les pertes sanguines augmentent de façon disproportionnée.

\section{REFERENCES}

1. Holr, J. P. The Collapse Factor in the Measurement of Venous Pressure. Am. J. Physiol. 134: 292 (1941)

2. Taylor, R. O.; Maxson, E. C.; Carter, F. H.; Bethand, W.; \& Prentiss, R. Volumetric, Gravimetric and Radio-isotope Determination of Fluid Transfer in Transurethral Prostatectomy. J. Urol. 79: 490 (1958). 